\title{
INCIDENCE OF TUBERCULOSIS INFECTION IN SPONDYLOARTHRITIS PATIENTS TREATED WITH BIOLOGICAL AND CONVENTIONAL DISEASE- MODIFYING ANTI-RHEUMATIC DRUGS IN AN ENDEMIC AREA
}

\author{
André Luis Bittencourt Morsch¹, Lilian Rodrigues Henrique ${ }^{4}$, \\ Denise Rossato Silva ${ }^{2,3}$, Giovana Garziera ${ }^{2,3}$, Ricardo \\ Machado Xavier ${ }^{1,4}$, Vanessa Hax ${ }^{1}$, Manoela Fantinel Ferreira ${ }^{1}$, \\ Charles Lubianca Kohem ${ }^{1,4}$, Aline Castello Branco Mancuso ${ }^{5}$, \\ Andrese Aline Gasparin ${ }^{1}$, Claiton Viegas Brenol ${ }^{1,4}$, \\ Nicole Pamplona Bueno de Andrade ${ }^{1}$, Franciele de Almeida Menegat ${ }^{1}$, \\ Daniela Viecceli ${ }^{1}$, Renata Bohn ${ }^{4}$, Penélope Esther Palominos ${ }^{1}$
}

\begin{abstract}
Introduction: Registries of spondyloarthritis (SpA) patients' follow-up provided evidence that tumor necrosis factor inhibitors (TNFi) increase the incidence of active tuberculosis infection (TB). However, most of these registries are from low burden TB areas. Few studies evaluated the safety of biologic agents in TB endemic areas. This study compares the TB incidence rate (TB IR) in anti-TNF-naïve and anti-TNFexperienced subjects with SpA in a high TB incidence setting.
\end{abstract}

Methods: In this retrospective cohort study, medical records from patients attending a SpA clinic during 13 years (2004 to 2016) in a university hospital were reviewed. The TB IR was calculated and expressed as number of events per $10^{5}$ patients/year; the incidence rate ratio (IRR) associated with the use of TNFi was calculated.

Results: A total of 277 patients, 173 anti-TNF-naïve and 104 anti-TNF-experienced subjects, were evaluated; $35.7 \%(\mathrm{~N}=35)$ of patients who were prescribed an antiTNF drug were diagnosed with latent tuberculosis infection (LTBI). Total follow-up time (person-years) was 1667.8 for anti-TNF-naïve and 394.9 for anti-TNF-experienced patients. TB IR $(95 \% \mathrm{Cl})$ was 299.8 (37.4-562.2) for anti-TNF naïve and 1012.9 (25.3-2000.5) for anti-TNF experienced subjects. The IRR associated with the use of TNFi was 10.4 (2.3- 47.9).

Conclusions: In this high TB incidence setting, SpA patients exposed to anti-TNF therapy had a higher incidence of TB compared to anti-TNF-naïve subjects, although the TB incidence in the control group was significant.

Keywords: Spondyloarthritis; tuberculosis; anti-TNF therapy; tumor necrosis factor alpha; tuberculin skin test

Tumor necrosis factor inhibitors (TNFi), also called anti-TNF agents, have emerged as an effective treatment in immune-mediated diseases and are associated with clinical benefits in patients with spondyloarthritis $(\mathrm{SpA})^{1}$. However, they may induce progression from latent tuberculosis infection (LTBI) to active tuberculosis (TB) ${ }^{2}$. Cases of TB have been associated with TNFi use in patients with rheumatic diseases ${ }^{3-6}$.

The American College of Rheumatology (ACR) recommends LTBI screening for patients who are candidates for anti-TNF therapy, with either tuberculin skintest (TST) or interferon-gamma release assay (IGRA). It also recommends that patients who live in high TB incidence settings should be tested annually for $\mathrm{LTBI}^{7}$. However, TB cases developed despite the screening and treatment for $\left.L T B\right|^{3-6,8-}$ ${ }^{10}$. Indeed, LTBI diagnosis is difficult in patients already on immunosuppressive medications (disease modifying antirheumatic drugs [DMARDs] and steroids) because of false-negative TST results ${ }^{11}$. In addition, low compliance with LTBI
Clin Biomed Res. 2020;40(1):1-6

1 Serviço de Reumatologia, Hospital de Clínicas de Porto Alegre (HCPA).

Porto Alegre, RS, Brasil.

2 Serviço de Pneumologia, Hospital de Clínicas de Porto Alegre (HCPA). Porto Alegre, RS, Brasil.

3 Programa de Pós-Graduação em Ciências Pneumológicas, Universidade Federal do Rio Grande do Sul (UFRGS). Porto Alegre, RS, Brasil.

4 Faculdade de Medicina, Universidade Federal do Rio Grande do Sul (UFRGS). Porto Alegre, RS, Brasil.

5 Serviço de Bioestatística, Hospital de Clínicas de Porto Alegre (HCPA). Porto Alegre, RS, Brasil.

Corresponding author: Lilian Rodrigues Henrique Ihenrique@hcpa.edu.br Faculdade de Medicina, Universidade Federal do Rio Grande do Sul (UFRGS) Rua Ramiro Barcelos, 2400. 90035-002, Porto Alegre, RS, Brasil. 
treatment is another explanation to TB occurrence during anti-TNF therapy ${ }^{12}$. Furthermore, in highly endemic areas, TB cases in patients exposed to TNFi could be a consequence of new infection ${ }^{3-6}$.

Previous studies describing TB infection during anti-TNF therapy included mostly patients with rheumatoid arthritis, living in low burden TB areas and outside Latin America ${ }^{3-6,9}$. Then, the objective of the present paper was to study the safety of TNFi in a resource-poor country, evaluating the TB incidence rate in TNFi-naïve and TNFi-experienced subjects with SpA in a high TB incidence setting.

\section{METHODS}

A retrospective cohort study was conducted in a public tertiary university hospital located in Porto Alegre, a city in southern Brazil with a high incidence of TB, where 88.8 cases were diagnosed per 100,000 population in $2015^{13}$. Electronic medical records from patients attending the SpA clinic between July 2004 and December 2016 were reviewed. Age, gender, self-reported ethnicity, time since the SpA diagnosis, past or current use of TNFi, history of TB and/or LTBI, as well as TST and chest radiograph results before the first TNFi were recorded.

The "on drug" model was used, i.e., TB cases were attributed to anti-TNF therapy if the patient was actively receiving the drug at the time of diagnosis ${ }^{14,15}$. The date of TNFi discontinuation was taken as the first missed dose. The follow-up period was considered as the time between the first visit to the SpA clinic and the most recent follow-up visit or death; follow-up was not censored at the time of TB diagnosis. Patients could restart treatment following an episode of TB, either resuming prior treatment or switching drugs. Subjects in the comparison arm who were prescribed a TNFi contributed person-years to the comparison cohort up to the date this drug was started and subsequent follow-up to the TNFi cohort. Patients initially registered in the anti-TNF arm could not contribute to the comparator arm when the antiTNF drug was stopped.

TB cases were considered "confirmed cases" if they were culture positive and/or acid fast bacillus smear positive. Patients with a physician-determined diagnosis of TB without these criteria were considered "unconfirmed cases".

Continuous variables were reported as mean and standard deviation (SD) or median and interquartile range; categorical variables were expressed as absolute and relative frequency. The tuberculosis incidence rate (TB IR) was reported as events $/ 10^{5}$ person-years with $95 \%$ confidence interval $(95 \% \mathrm{Cl})$. The TB incidence rate ratio (TB-IRR) was calculated using Cox regression, comparing the TNFi-naïve and TNFi-experienced cohorts, with adjustments for age, gender and ethnicity. To compare other characteristics between cohorts, the Pearson's chi-square or Fisher's exact, Mann-Whitney or Student's t tests were used. Significance level was defined as $p$-value lower than 0.05. The SPSS version 18.0.0 was used ${ }^{16}$.

The study was approved by the institutional Ethics Committee at Hospital de Clínicas de Porto Alegre, (GPPG 170231, approval number 2031188), and investigators signed an informed consent for use of patients' data.

\section{RESULTS}

A total of 277 patients were evaluated, 173 TNFinaïve and $104 \mathrm{TNFi}$-experienced. Those exposed to anti-TNF drugs were diagnosed with $\mathrm{SpA}$ in a younger age and were more frequently men than anti-TNF naïve patients (Table 1).

Ankylosing spondylitis $(41.5 \%, \mathrm{~N}=111)$ and psoriatic arthritis $(39.0 \%, \mathrm{~N}=108)$ were the most common diagnoses.

Total follow-up time (in person-years) was 1667.8 for the TNFi-naïve cohort and 394.9 for the TNFiexperienced cohort. The median (IQR, 25-75\%) duration of follow-up per patient was 6.1 (1.7-10.6) years for the TNFi-naïve group and 3.8 (2.0-4.9) years for subjects previously exposed to anti-TNF therapy. About $35.0 \%$ of subjects (97/277) switched from the TNFi-naïve to the TNFi-experienced group and contributed person-years to both cohorts.

Among the TNFi-experienced cohort, $67.3 \%(\mathrm{~N}=70)$, $34.1 \%(\mathrm{~N}=36)$ and $27.9 \%(\mathrm{~N}=29)$ of patients were exposed to adalimumab, etanercept and infliximab, respectively. The median duration "on drug" (IQR, 25$75 \%$ ) was 2.8 (1.6-4.4) for adalimumab, 1.7 (0.7-4.1) for etanercept and 2.1 (0.8-4.4) for infliximab. Only one patient was exposed to golimumab and no one was exposed to certolizumab as these drugs were not available in the public health system at the time of study conduction.

From the 104 subjects who were prescribed anti-TNF therapy, $98.1 \%(\mathrm{~N}=101)$ underwent chest radiography and $95.2 \%(\mathrm{~N}=99)$ underwent TST before starting the first anti-TNF drug. Among the patients who had both TST and chest radiograph available $(94.2 \%$, $\mathrm{N}=98 / 104), 35.7 \%(\mathrm{~N}=35)$ were diagnosed with LTBI. Among patients with LTBI, $94.3 \%(\mathrm{~N}=33 / 35)$ were diagnosed because of TST $\geq 5 \mathrm{~mm}$ and $5.7 \%$ (2/35) because of abnormal chest radiograph. All patients diagnosed with LTBI underwent 6 months of isoniazid preventive therapy (IPT) and TNFi was started after at least 1 month of IPT.

There were 9 cases of TB: 5 in the TNFi-naïve and 4 in the TNFi-experienced cohort (Table 2). Among the 4 patients treated with TNFi who developed TB, 2 had negative screening for $L T B I, 1$ was diagnosed with $L T B I$ and treated with isoniazid before starting biological 
Table 1: Characteristics of the 277 subjects included in the analysis

\begin{tabular}{lccc}
\hline \multicolumn{1}{c}{ Characteristics } & $\begin{array}{c}\text { Anti-TNF-naïve } \\
\mathbf{N}=\mathbf{1 7 3}\end{array}$ & $\begin{array}{c}\text { Anti-TNF-experienced } \\
\mathbf{N}=\mathbf{1 0 4}\end{array}$ & P-value \\
\hline $\begin{array}{l}\text { Age at time of SpA diagnosis, } \\
\text { years (mean } \pm \text { SD) }\end{array}$ & $44.8 \pm 14.4$ & $39.2 \pm 11.9$ & $<0.001$ \\
Female gender, N (\%) & $92(53.2)$ & $41(39.4)$ & 0.036 \\
Disease duration, years & 10.7 & 10.7 & 0.615 \\
(median [IQR, 25-75\%]) & $(5.7-19.7)$ & $(6.7-17.4)$ & 0.709 \\
Self-reported white ethnicity, N (\%) & $163(94.2)$ & $96(92.3)$ & \\
\hline
\end{tabular}

IQR: interquartile range; N: number; SD: standard deviation; SpA: spondyloarthritis; TNF: tumor necrosis factor.

therapy, and 1 had no TST available in medical records. Individuals who developed TB during anti-TNF treatment were frequently diagnosed with disseminated infection $(75 \%, N=3)$, and all were diagnosed with TB more than 1 year after starting TNFi (Table 2).
Patients with SpA exposed to TNFi had a higher incidence of TB compared to those who had never been exposed to these drugs: the TBIR in cases $/ 10^{5}$ patient/year $(95 \% \mathrm{Cl})$ was 299.8 (37.4-562.2) in the TNFi-naïve cohort versus 1012.9 (25.3-2000.5) in

Table 2. Characteristics of spondyloarthritis patients diagnosed with tuberculosis

\begin{tabular}{|c|c|c|c|c|c|c|c|c|c|}
\hline $\begin{array}{c}\text { Case } \\
\text { number }\end{array}$ & $\begin{array}{c}\text { Gender } \\
\text { ( } M=\text { male, } \\
\text { F = female) }\end{array}$ & $\begin{array}{c}\text { Self- } \\
\text { reported } \\
\text { ethnicity }\end{array}$ & $\begin{array}{l}\text { Age at TB } \\
\text { diagnosis } \\
\text { (in years) }\end{array}$ & $\begin{array}{c}\text { TB } \\
\text { confirmed } \\
\text { case? }\end{array}$ & $\begin{array}{l}\text { Clinical } \\
\text { form } \\
\text { of TB }\end{array}$ & $\begin{array}{c}\text { SpA } \\
\text { subtype }\end{array}$ & $\begin{array}{c}\text { Current } \\
\text { treatment } \\
\text { when TB was } \\
\text { diagnosed }\end{array}$ & $\begin{array}{c}\text { Delay } \\
\text { between } \\
\text { the first } \\
\text { dose of } \\
\text { anti-TNF } \\
\text { drug } \\
\text { and TB } \\
\text { diagnosis } \\
\text { (in years) }\end{array}$ & $\begin{array}{c}\text { TST } \\
\text { before } \\
\text { anti- } \\
\text { TNF } \\
\text { therapy } \\
\text { (in mm) }\end{array}$ \\
\hline \multicolumn{10}{|c|}{ SUBJECTS EXPOSED TO ANTI-TNF THERAPY } \\
\hline 1 & $\mathrm{M}$ & White & 56 & Yes & Disseminated & AS & $\begin{array}{c}\text { ADA } 40 \text { mg EOW } \\
+ \text { MTX } 20 \mathrm{mg} / \\
\text { week }\end{array}$ & 1.6 & $8^{*}$ \\
\hline 2 & $\mathrm{~F}$ & White & 44 & Yes & Pulmonary & AS & ADA $40 \mathrm{mg} \mathrm{EOW}$ & 5.0 & unknown \\
\hline 3 & M & White & 61 & Yes & Disseminated & PsA & $\begin{array}{c}\text { ADA } 40 \text { mg EOW } \\
\text { + MTX } 17.5 \mathrm{mg} / \\
\text { week }\end{array}$ & 4.2 & 0 \\
\hline 4 & M & White & 72 & No & Disseminated & PsA & $\begin{array}{c}\text { ADA } 40 \text { mg EOW } \\
\text { + MTX } 15 \mathrm{mg} / \\
\text { week }\end{array}$ & 5.4 & 0 \\
\hline \multicolumn{10}{|c|}{ SUBJECTS NONEXPOSED TO ANTI-TNF THERAPY } \\
\hline 5 & $\mathrm{~F}$ & White & 48 & No & Pulmonary & AS & $\begin{array}{c}\text { NSAID + } \\
\text { prednisone } \\
5 \mathrm{mg} / \text { day }\end{array}$ & - & - \\
\hline 6 & M & White & 67 & No & Pulmonary & PsA & $\begin{array}{c}\text { MTX } 15 \mathrm{mg} / \text { week } \\
+ \text { LEF } 20 \mathrm{mg} / \\
\text { day + prednisone } \\
5 \mathrm{mg} / \text { day }\end{array}$ & - & - \\
\hline 7 & $M$ & White & 68 & Yes & Pulmonary & AS & NSAID & - & - \\
\hline 8 & $M$ & White & 59 & No & Adrenal & AS & $\begin{array}{c}\text { SSZ } 1500 \text { mg/ } \\
\text { day }\end{array}$ & - & - \\
\hline 9 & $\mathrm{~F}$ & White & 58 & Yes & Pulmonary & PsA & LEF 20 mg/day & - & - \\
\hline
\end{tabular}

ADA: adalimumab; AS: ankylosing spondylitis; EOW: every other week; LEF: leflunomide; MTX: methotrexate; NSAID: nonsteroidal antiinflammatory drug; PsA: psoriatic arthritis; SpA: spondyloarthritis; SSZ: sulfasalazine; TB: active tuberculosis infection; TNF: tumor necrosis factor; *: patient underwent 6 months of isoniazid preventive therapy. 
the TNFi-experienced cohort. The TB IRR $(95 \% \mathrm{CI})$ associated with the use of anti-TNF therapy was 10.4 (2.3-47.9) and did not change after adjustments for age, gender and ethnicity. It was not possible to compare the TB risk among the various anti-TNF agents as the number of patients on each drug was small.

\section{DISCUSSION}

The analysis of $\mathrm{SpA}$ patients living in this resourcepoor country in Latin America produced three main results: 1) the TNFi-experienced SpA patients had a higher incidence of TB compared to those who had never been exposed to these drugs, 2) the TNFinaïve patients, i.e., those only taking conventional DMARDs and NSAIDs had a high TB incidence and LTBI screening should also be considered in this population, 3) one-third of SpA patients who underwent screening for LTBI before starting biological therapy were diagnosed with LTBI.

Our results are in accordance with previous research which demonstrated TNFi to increase the incidence rate of TB in SpA patients living in intermediate-burden areas and also in high-burden areas in developed countries ${ }^{17,18}$.

TNF has been demonstrated to play a major role in the formation of granulomas, during macrophage activation as well as cell recruitment to the site of infection $^{19-21}$. Therefore, inhibition of TNF is the biological basis by which TNFi increased the risk of disease by inducing the progression from LTBI to active TB2. In our study, $35.7 \%$ of SpA patients were diagnosed with LTBI. This prevalence is slightly smaller than that found in the district of Seine-Saint-Denis, France, where $47.2 \%$ of patients with inflammatory rheumatic diseases were TST-positive ${ }^{22}$. Lower prevalence of LTBI was described by other studies conducted in Brazil (13.4\% and 27.0\%), Peru $(29.0 \%)$ and India $(20.4 \%)^{23-26}$. However, these studies included mostly rheumatoid arthritis patients, known to have decreased TST positivity attributable to a defect in cellular immunity ${ }^{27-30}$. In fact, in a case-control study conducted in Turkey, the frequency of TST positivity in patients with rheumatoid arthritis $(29.8 \%)$ was lower than in patients with ankylosing spondylitis $(65.9 \%)^{31}$. In another study, LTBI prevalence was higher in patients with ankylosing spondylitis (37.6\%) than in those with rheumatoid arthritis $(12.8 \%)$ and psoriatic arthritis $(18.8 \%)^{32}$.

There were 9 cases of TB in the present study: 5 among TNFi-naïve and 4 among TNFi-experienced individuals. The incidence rate of TB among TNFinaïve patients 299.8 cases (37.4-562.2)/105 patients/ year was significant in this TB endemic area. Possible explanations for the occurrence of TB in TNFi-naïve subjects are the use of other immunosuppressive medications such as conventional DMARDs and steroids, which can also increase the risk of TB, although in a lesser extent than anti-TNF agents. Also, these patients live in an endemic area, where continuous and repeated exposure to TB is likely. Although recent research showed that in a low TB risk area biological-naïve SpA are not at an increased TB risk ${ }^{33}$, our study demonstrated that in endemic TB areas this group of patients had a high incidence of TB. Thus, LTBI screening should be considered even in TNFi-naïve subjects, especially in those taking corticosteroids and/or conventional DMARDs. The screening for LTBI in Brazil is restricted to patients exposed to anti-TNF alpha and patients receiving $\geq 15 \mathrm{mg} /$ day prednisone or equivalent for more than 1 month $^{34}$.

Among the 4 TB cases reported in TNFi-experienced subjects, 2 had negative screening for LTBI and 1 underwent IPT before starting the anti-TNF agent. Furthermore, all TNFi-experienced patients who developed TB were diagnosed with this condition more than 1 year after exposure to biological therapy, indicating that they were most likely newly acquired infections.

TB cases during anti-TNF treatment are usually a consequence of new infection or reactivation of LTBI not diagnosed during screening (due to a falsenegative TST) $)^{3-6}$. This reinforces the need of TST repetition during anti-TNF treatment ${ }^{7}$. In addition, TB cases have been described during anti-TNF therapy even in patients with previous LTBI treatment ${ }^{10}$ as IPT cannot prevent the development of TB via new infection, especially in highly endemic areas.

This study has some limitations that we must take into account. First, we analyzed information from a single hospital. However, we believe the results may apply to other settings, especially TB endemic areas. Second, the exposure status and outcomes were ascertained retrospectively based on information found in medical records. Despite the retrospective design, there were few missing values. Third, the calculated TBIR had large confidence intervals because of the small number of TB cases in the sample. In spite of these concerns, knowledge of the incidence of TB during anti-TNF treatment in patients with SpA is important to define the best approach for LTBI screening in those patients from populations at risk.

In conclusion, we found that, in a region with high TB prevalence in a resource-poor country, patients with SpA exposed to TNFi had a higher incidence of TB compared to those who had never been exposed to these drugs. Additionally, a high percentage of SpA patients were diagnosed with LTBI. Physicians should be aware of the possibility of TB development during anti-TNF therapy, even after LTBI treatment. Also, our data reinforces the ACR's recommendation that patients who live in endemic settings should be tested annually for $\mathrm{LTBI}^{7}$. 


\section{Conflict of interest}

The authors declare no conflict of interest.

\section{Financial support}

None.

\section{REFERENCES}

1. Palladino MA, Bahjat FR, Theodorakis EA, Moldawer LL. Anti-TNF-alpha therapies: the next generation. Nat Rev Drug Discov. 2003;2(9):736-46.

2. Keane J, Gershon S, Wise RP, Mirabile-Levens E, Kasznica J, Schwieterman WD, et al. Tuberculosis associated with infliximab, a tumor necrosis factor alphaneutralizing agent. $N$ Engl J Med. 2001;45(15):1098-104.

3. Chen DY, Shen GH, Chen YM, Chen $\mathrm{HH}$, Hsieh CW, Lan JL. Biphasic emergence of active tuberculosis in rheumatoid arthritis patients receiving TNF alpha inhibitors: the utility of IFN gamma assay. Ann Rheum Dis. 2012;71(2):231-7.

4. Hsia EC, Cush JJ, Matteson EL, Beutler A, Doyle MK, Hsu B, et al. Comprehensive tuberculosis screening program in patients with inflammatory arthritides treated with golimumab, a human anti-tumor necrosis factor antibody, in Phase III clinical trials. Arthritis Care Res (Hoboken). 2013;65(2):309-13.

5. Raval A, Akhavan-Toyserkani G, Brinker A, Avigan M. Brief communication: characteristics of spontaneous cases of tuberculosis associated with infliximab. Ann Intern Med. 2007;147(10):699-702.

6. Westhovens R, Yocum D, Han J, Berman A, Strusberg I, Geusens P, et al. The safety of infliximab, combined with background treatments, among patients with rheumatoid arthritis and various comorbidities: a large, randomized, placebo-controlled trial. Arthritis Rheum. 2006;54(4):1075-86.

7. Singh JA, Furst DE, Bharat A, Curtis JR, Kavanaugh AF, Kremer JM, et al. 2012 update of the 2008 American College of Rheumatology recommendations for the use of disease-modifying antirheumatic drugs and biologic agents in the treatment of rheumatoid arthritis. Arthritis Care Res (Hoboken). 2012;64(5):625-39.

8. Abitbol $\mathrm{Y}$, Laharie $\mathrm{D}$, Cosnes $\mathrm{J}$, Allez M, Nancey S, Amiot A, et al. Negative Screening Does Not Rule Out the Risk of Tuberculosis in Patients with Inflammatory Bowel
Disease Undergoing Anti-TNF Treatment: A Descriptive Study on the GETAID Cohort. J Crohns Colitis. 2016;10(10):1179-85.

9. Cantini F, Lubrano E, Marchesoni A, Mathieu A, Olivieri I, Salvarani C, et al. Latent tuberculosis infection detection and active tuberculosis prevention in patients receiving anti-TNF therapy: an Italian nationwide survey. Int $\mathrm{J}$ Rheum Dis. 2016;19(8):799-805.

10. Lee JW, Choi CH, Park JH, Kim JW, Kang SB, Koo JS, et al. Clinical features of active tuberculosis that developed during anti-tumor necrosis factor therapy in patients with inflammatory bowel disease. Intest Res. 2016;14(2):146-51.

11. Ponce de León $D$, Acevedo-Vásquez E, Sánchez-Torres A, Cucho M, Alfaro $\mathrm{J}$, Perich R, et al. Attenuated response to purified protein derivative in patients with rheumatoid arthritis: study in a population with a high prevalence of tuberculosis. Ann Rheum Dis. 2005;64(9):1360-1.

12. Sterling TR, Villarino ME, Borisov AS, Shang N, Gordin F, BlivenSizemore E, et al. Three months of rifapentine and isoniazid for latent tuberculosis infection. N Engl J Med. 2011;365(23):2155-66.

13. Ministério da Saúde (BR). Perspectivas brasileiras para o fim da tuberculose como problema de saúde pública. Bolet Epidemiol. 2016;47(13):1-14

14. Dixon WG, Symmons DP, Lunt M, Watson KD, Hyrich KL; British Society for Rheumatology Biologics Register Control Centre Consortium, et al. Serious infection following anti-tumor necrosis factor alpha therapy in patients with rheumatoid arthritis: lessons from interpreting data from observational studies. Arthritis Rheum. 2007;56(9):2896-904.

15. Dixon WG, Hyrich KL, Watson KD, Lunt M, Galloway J, Ustianowski A, et al. Drug-specific risk of tuberculosis in patients with rheumatois arthritis treated with anti-TNF therapy: results from the British Society for Rheumatology Biologics Register (BSRBR). Ann Rheum Dis. 2010;69:522-8.
16. SPSS Inc. PASW Statistics for Windows, version 18.0. Chicago: SPSS Inc; 2009.

17. Kim HW, Park JK, Yang JA, Yoon YI, Lee EY, Song YW, et al. Comparison of tuberculosis incidence in ankylosing spondylitis and rheumatoid arthritis during tumor necrosis factor inhibitor treatment in an intermediate burden area. Clin Rheumatol. 2014;33(9):1307-12.

18. Nisar MK, Rafiq A, Östör AJ. Biologic therapy for inflammatory arthritis and latent tuberculosis: real world experience from a high prevalence area in the United Kingdom. Clin Rheumatol. 2015;34(12):2141-5

19. Algood HM, Lin PL, Flynn JL. Tumor necrosis factor and chemokine interactions in the formation and maintenance of granulomas in tuberculosis. Clin Infect Dis. 2005;41 Suppl 3:S189-93.

20. Ehlers S. Tumor necrosis factor and its blockade in granulomatous infections: differential modes of action of infliximab and etanercept? Clin Infect Dis. 2005;41 Suppl 3:S199-203.

21. Lin PL, Plessner HL, Voitenok NN, Flynn JL. Tumor necrosis factor and tuberculosis. J Investig Dermatol Symp Proc. 2007;12(1):22-5.

22. Saidenberg-Kermanach $\mathrm{N}$, Semerano L, Naccache JM, Brauner M, Falgarone $G$, Dumont-Fischer $D$, et al. Screening for latent tuberculosis in anti-TNFalpha candidate patients in a high tuberculosis incidence setting. Int $\mathrm{J}$ Tuberc Lung Dis. 2012;16(10):1307-14.

23. Bonfiglioli KR, Ribeiro AC, Moraes JC, Saad CG, Souza FH, Calich AL, et al. LTBI screening in rheumatoid arthritis patients prior to anti-TNF treatment in an endemic area. Int $J$ Tuberc Lung Dis. 2014;18(8):905-11.

24. Callado MR, Lima JRC, Nobre CA, Vieira WP. Low prevalence of reactive PPD prior to infliximab use: comparative study on a population sample of Hospital Geral de Fortaleza. Rev Bras Reumatol. 2011;51(1):40-52. 
25. Agarwal S, Das SK, Agarwal GG, Srivastava R. Steroids Decrease Prevalence of Positive Tuberculin Skin Test in Rheumatoid Arthritis: Implications on Anti-TNF Therapies. Interdiscip Perspect Infect Dis. 2014;2014:430134.

26. Bartalesi F, Goletti D, Spinicci M, Cavallo A, Attala L, Mencarini J, et al. Serial QuantiFERON TB-gold intube testing during LTBI therapy in candidates for TNFi treatment. J Infect. 2013;66(4):346-56.

27. Emery P, Panayi G, Symmons D, Brown G. Mechanisms of depressed delayed-type hypersensitivity in rheumatoid arthritis: the role of protein energy malnutrition. Ann Rheum Dis. 1984;43(3):430-4.

28. Kim JH, Cho SK, Han M, Choi $\mathrm{CB}, \mathrm{Kim} \mathrm{TH}$, Jun JB, et al. Factors influencing discrepancies between the QuantiFERON-TB gold in tube test and the tuberculin skin test in Korean patients with rheumatic diseases. Semin Arthritis Rheum. 2013;42(4):424-32.

29. Paimela L, Johansson-Stephansson EA, Koskimies S, Leirisalo-Repo M. Depressed cutaneous cell-mediated immunity in early rheumatoid arthritis. Clin Exp Rheumatol. 1990;8(5):433-7.

30. Panayi GS, Corrigall VM, Pitzalis C. Pathogenesis of rheumatoid arthritis. The role of $\mathrm{T}$ cells and other beasts. Rheum Dis Clin North Am. 2001;27(2):317-34.

31. Koker IH, Pamuk ON, Karlikaya C, Tunçbilek N, Cakir N. A low prevalence of purified protein derivative test positivity in Turkish patients with rheumatoid arthritis. Association with clinical features and HRCT findings. Clin Exp Rheumatol. 2007;25(1):54-9.
32. Gomes CM, Terreri MT, Moraes-Pinto MI, Barbosa C, Machado NP, Melo MR, Pinheiro MM. Incidence of active mycobacterial infections in Brazilian patients with chronic inflammatory arthritis and negative evaluation for latent tuberculosis infection at baseline--a longitudinal analysis after using TNFa blockers. Mem Inst Oswaldo Cruz. 2015;110(7):921-8.

33. De Vries MK, Arkema EV, Jonsson J, Bruchfeld J, Jacobsson LTH, Askling J, ARTIS Study Group. ARTIS Study group. Tuberculosis risk in ankylosing spondylitis, other spondyloarthritis and psoriatic arthritis in Sweden: a populationbased cohort study. Arthritis Care Res (Hoboken). 2018;70(10):1563-7.

34. Ministério da Saúde (BR). Manual de recomendações para o controle da tuberculose no Brasil. Brasília; 2019.

Received: Nov 22, 2019

Accepted: Feb 28, 2020 